\title{
Use of PlanetScope Images in the burned areas monitoring program in parks and protected areas the IBRAM-PROMAQ
}

\author{
Airton Mauro de Lára Santos ${ }^{I}$, Albino Luciano Simões Antonio ${ }^{l}$, Danielly Ferreira ${ }^{l}$, Elenice dos \\ Santos Costa ${ }^{I}$, Petrônio Diego Silva de Oliveira ${ }^{I}$
}

\footnotetext{
${ }^{1}$ Instituto Brasília Ambiental (IBRAM), Brasília, Brasil

*e-mail: airton.santos@ibram.df.gov.br; albino.antonio@ibram.df.gov.br; danielly.ferreira@ibram.df.gov.br; elenice.costa@ibram.df.gov.br; petronio.olivera@ibram.df.gov.br
}

\begin{abstract}
The Monitoring Program of Burned Areas in the Parks and Conservation Units (UC's) under the management of the Environmental Brasilia Institute - IBRAM (PROMAQ, Federal District) is an annual program, started in 2010, with the aim of quantifying outbreaks of forest fires and measure the areas burned in Parks and UC's. The survey of the burned areas takes place remotely, using PlanetScope. This survey is done on a monthly basis, during the period from January to May and from October to December and fortnightly from June to September. Then, for each area is filled specific form. With basis in this record is done the georeferencing of the areas affected by forest fires. In the year 2018, were monitored 76 parks and UC under management of IBRAM. Of this total, were recorded and mapped areas burned in 55, being filled 505 records, totaling a burnt area mapped 1,715.46 acres. In the year 2018, despite an increase in the number of forest fires records, when compared with previous years, there was a decrease in the burned area, making it the year with the lowest number of area burned since beginning of PROMAQ. The increase in the number of records can be explained by the use of PlanetScope high resolution images, which presented a significant evolution in the survey of the burned areas, areas previously inaccessible that now are monitored. Another factor to be considered is the temporality of analysis of images, from 30 to 15 days and may make differentiation of burned areas adjoining, which often was not possible in the field, i.e., a burned area could be considered as only a record, when in fact it could be formed by several outbreaks of different fires. In spite of the increase of the number of records it was observed that there was a decrease in the amount of already burned areas due, among other factors, to the change in rainfall when compared with previous years. Another possible explanation for the decrease in the amount of burned areas, is the fact the IBRAM have hired 100 professionals specialized in fighting forest fires, among brigades, brigades and squadron chiefs, which were distributed in Parks and UC's under the management of IBRAM.
\end{abstract}

Keywords: forest fire Monitoring, remote sensing, PlanetScope, Federal District. 